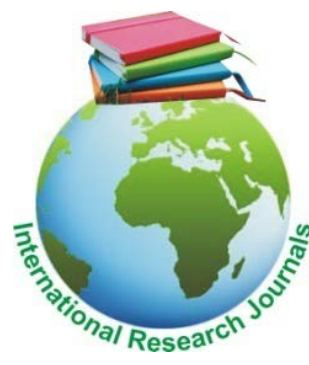

African Journal of Food Science and Technology (ISSN: 2141-5455) Vol. 9(2) pp. 25-31, July, 2018

DOI: http:/dx.doi.org/10.14303/ajfst.2018.231

Available online https://www.interesjournals.org/food-science-technology.html

Copyright (C2018 International Research Journals

Full Length Research Paper

\title{
Optimization of miracle fruit (Synsepalum dulcificum) seed germination and mutagenesis
}

\author{
Alan Chambers*, Lynhe Demesyeux, Pamela Moon, Yuqing Fu \\ Tropical Research and Education Center, University of Florida, Homestead, Florida. ac@ufl.edu
}

\begin{abstract}
Interest in miracle fruit for reducing sugar content in food and beverages is increasing, but miracle fruit genetic improvement is hindered by delayed seed germination, slow seedling growth, and a lack of readily available genetic diversity. Preliminary studies were conducted to optimize the effects of seed surface sterilization, drying time, incubation temperature, and the presence or absence of the seed coat on miracle fruit germination. Optimal 10 days germination rates and seedling growth were realized by omitting surface sterilization, decreasing postharvest drying time, incubating at $30^{\circ} \mathrm{C}$, and removal of the seed coat. Removal of the seed coat alone increased germination by $53 \%$ after ten days under optimal conditions. Root and shoot lengths were maximized at 8.73 $\mathrm{mm}$ and $2.87 \mathrm{~mm}$, respectively, after 10 days incubations under optimal conditions. Experiments using $\gamma$-ray mutagenesis were conducted as a means to create genetic diversity in this species. Irradiation levels from 0 to 600 Gy resulted in a calculated LD50 at $\sim 70$ Gy with total seed mortality at $400 \mathrm{~Gy}$. Finally, the frequency of seeds with three cotyledons and double seeds (3.8\% and $0.43 \%$, respectively) were observed in multiple harvests. These findings describe conditions that increase germination percentage, maximize seedling growth rate, and establish a range of radiation levels to create miracle fruit mutation populations for the genetic improvement of this valuable species.
\end{abstract}

Keywords: Irradiation, miracle berry, three cotyledons, double seeds.

\section{INTRODUCTION}

Natural, low calorie sweeteners like miraculin from miracle fruit (Synsepalum dulcificum) are increasing in popularity, but foundational studies to guide formal improvement of this species are lacking. Miracle fruit is a native to West Africa and has been used locally for over 100 years for its taste-modifying properties (Achigan-Dako et al., 2015; Daniell, 1852). The pulp of the fruit contains a glycoprotein, miraculin that has potent sensory sweetening effects (Gibbs et al., 1996; Kant, 2005; Temussi, 2006; Wong and Kern, 2011). Although tasteless itself, miraculin has a sweetening effect on acidic food and beverages that is estimated to be about 400,000 times greater than sucrose (Kurihara and Beidler, 1968), and the effect lasts for 30 to $60 \mathrm{~min}$ (Inglett et al., 1965; Kurihara and Beidler, 1968; Theerasilp et al., 1989). Tablets made from lyophilized miracle fruit juice are available through online vendors, and are also being tested in clinical studies to mask the negative sensory side effects of cancer treatments (Wilken and Satiroff, 2012). While the benefits of miraculin are actively being studied, more research is needed to characterize, optimize and improve its natural botanical source. Plant breeding could be a means towards improving the quantity and quality of miraculin and the species' overall agronomic performance, but the requisite foundational studies required to support any plant improvement program are largely lacking. Optimizing seed germination and increasing the available genetic diversity are therefore two priorities for this species.

One major limitation to the genetic improvement of miracle fruit is seed germination. Miracle fruit seeds are sensitive to post-harvest environmental conditions and require careful handling to maintain viability. Microbial antagonists, suboptimal storage temperatures, seed desiccation, and physical barriers to germination were hypothesized to play major roles in miracle fruit seed viability. Previous studies found germination rates of $79 \%$ at $18^{\circ} \mathrm{C}$ after 15 days and $79-89 \%$ germination at $28-30^{\circ} \mathrm{C}$ after 27 days, but these studies were not replicated (Adansi and Holloway, 1975). A recent study found that prolonged seed storage past 7 days at ambient temperatures $\left(25^{\circ} \mathrm{C}\right)$ decreased miracle fruit seed germination to $0 \%$ (Tchokponhoue et al., 2018). Other foundational work 
for miracle fruit includes floral biology studies on fruit set and development (Ayensu, 1972; Xingwei et al., 2016), optimized cultural practices to accelerate immature seedling growth rate (Tchokponhoue et al., 2017), and genetic diversity of 40 Nigerian accessions using RAPD genetic markers (Chibuzor et al., 2016). These studies provide useful background information on miracle fruit, and additional research could rapidly bring this species into the modern era of plant improvement.

Genetic resources are key to plant improvement. These resources are scarce for miracle fruit even in the native countries (Achigan-Dako et al., 2015), though some germplasm collections exist. Collecting and characterizing miracle fruit genetic resources is imperative to support genetic improvement of this species. In the absence of readily available diverse genetic sources, diversity can be created, to a limited extent, through mutagenesis as has been done in other plant species (Ahloowalia and Maluszynski, 2001; Roychowdhury and Tah, 2013). Some mutagens, including ionizing radiation, induce double stranded DNA breaks that can result in gene knockouts that generate novel phenotypes. Chemical mutagens such as ethyl methanesulfonate (EMS) induce DNA point mutations. Both methods have been used in many species to create diversity, and the greatest efficiency is obtained when large numbers of individuals can be screened for easily scored phenotypes. Limitations to employing mutagenesis-based plant improvement of miracle fruit is the 3-4 year juvenility period (Tchokponhoué et al., 2017), because mutated plants often require a selfing generation to obtain a portion of homozygous altered alleles.

The following studies were designed to optimize environmental conditions to maximize miracle fruit seed germination and early growth. Additionally, mutagenesis rates have not yet been established for this unique species, and were empirically determined as part of this work.

\section{MATERIALS AND METHODS}

\section{Fruit Harvesting}

Miracle fruit berries were harvested by hand from mature plants growing in a shade house in Homestead, Florida, USA. Fruit were harvested according to established commercial practices when the entire outer peel turned a bright red color. Fruit peel and pulp were mechanically removed until polished seeds were obtained. Seed lots from independent harvests were used as treatment replicates. Only fully mature, whole, and undamaged seeds were used in this study.

\section{Surface Sterilization}

Seeds for surface sterilization experiments were dried in a single layer for $24 \mathrm{~h}$ at $23^{\circ} \mathrm{C}$. Drying resulted in brittle seed coats and facilitated their removal. After drying and seed coat removal, bare seeds were treated in $50 \mathrm{~mL}$ of: a) culinary water, b) $0.825 \%$ sodium hypochlorite, c) $3 \%$ hydrogen peroxide, and d) $2 \%$ sodium dichloroisocyanurate (NaDCC) for 20 min with agitation. The seeds were then rinsed three times in culinary water, sown on top of moist vermiculate in polypropylene boxes with loose fitting lids, and incubated at $30^{\circ} \mathrm{C}$ for 10 days. Germination and microbial growth were scored as yes/no or present/absent, respectively. The surface sterilization experiments included 30 seeds per treatment, and each treatment was replicated three times using seeds from a single harvest.

\section{Germination Experiments}

Seeds were dried in a single layer at $23^{\circ} \mathrm{C}$ for 0,1 , or 2 days for germination experiments. After drying, seed coats were either removed or left intact and seeds were incubated at $23^{\circ} \mathrm{C}, 30^{\circ} \mathrm{C}$ or $37^{\circ} \mathrm{C}$ on moist vermiculite in polypropylene boxes with loose fitting lids. Germination was scored as +/- if the emerging root exceeded beyond $1 \mathrm{~mm}$ in length after 10 days. Each experiment had three replicates of ten seeds per treatment, and each experiment was repeated three times with seeds from independent harvests.

\section{Root and Shoot Length Measurements}

Root and shoot lengths were measured from the tip of the root or shoot to the embryo using a ruler after 10 days of incubation. A complete factorial design included three post-harvest drying periods $(0,1$, or 2 days), three incubation temperatures $\left(23^{\circ} \mathrm{C}, 30^{\circ} \mathrm{C}\right.$, or $\left.37^{\circ} \mathrm{C}\right)$, and the presence or absence of the seed coat. Each experiment had three replicates of ten seeds per treatment, and each experiment was repeated three times with seeds from independent harvests.

\section{Mutagenesis Experiments}

Cesium-137 was used as a source for $\mathrm{y}$-ray mutagenesis. Batches of miracle fruit seeds with intact seed coats were treated at 0,50, 100, 200, 400, or 600 Gy. Seeds were not dried prior to irradiation, and were shipped and irradiated in moist vermiculite in zip closure bags. Treated seeds were sown in a single layer in 50: 50 soilless mix: perlite and grown in a shade house at an average temperature of $30^{\circ} \mathrm{C}$. Only seedlings producing a true leaf after 60 days were counted as viable. Each treatment at 0, 50, 100, 200, 400, or 600 Gy included 300 seeds, and each treatment was replicated three times.

\section{Statistics}

Factorial analysis was performed using SAS JMP Pro v13. The impacts of drying days, temperature, and presence/ absence of the seed coat on germination were modeled in JMP using a generalized linear model, binomial distribution, 
and logit link function. Drying days, temperature, and seed coat were analyzed for significant effects on root and shoot length using a standard least squares model. All graphs were created using SAS JMP Pro v13.

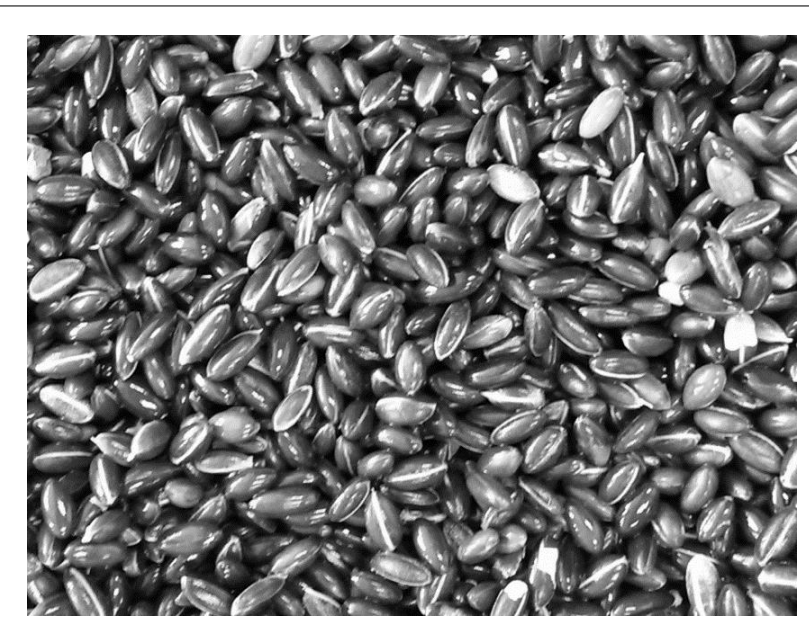

Figure 1: Cleaned miracle fruit seeds without remnants of peel or pulp. Only clean and undamaged seeds were used in this study.

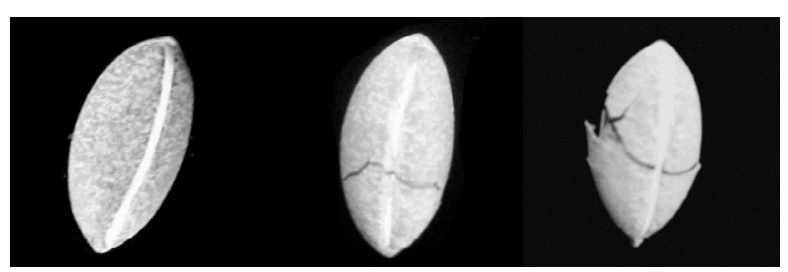

Figure 2: Qualitative examples of miracle fruit seed coats cracking in response to post-harvest drying at $23^{\circ} \mathrm{C}$. Representative samples are shown from 0 days (left), 1 day (middle), and 2 days (right) drying.

\section{RESULTS}

\section{Surface Sterilization}

All surface sterilization treatments reduced seed germination compared to water controls. The pulp of the miracle fruit berry clings to the seed and must be removed prior to germination to reduce microbial contamination. One representative batch of cleaned seeds is shown in Figure 1. Preliminary observations showed that rapidly growing microbial contaminants quickly cover germinating miracle fruit seeds. We therefore investigated the impact of surface sterilization on seed germination and microbial growth. Germination percentages were 53\% for the water control, $47 \%$ for $10 \%$ bleach, $43 \%$ for $3 \% \mathrm{H}_{2} \mathrm{O}_{2}$, and $17 \%$ for the 2\% NaDCC treatments. Microbial growth over the seed surface was observed for $13 \%, 30 \%, 6 \%$, and $70 \%$ for the water, $10 \%$ bleach, $3 \% \mathrm{H}_{2} \mathrm{O}_{2}$, and $2 \% \mathrm{NaDCC}$ treatments, respectively. This general trend suggests that $2 \%$ NaDCC negatively affected germination and resulted in increased microbial growth over the seed surface.

\section{Seed Coat, Drying Days, and Incubation Temperature Impacts on Seed Germination}

Miracle fruit seed germination is known to be negatively impacted by delayed post-harvest planting and incubation temperature (Adansi and Holloway, 1975). Renewed interest in miracle fruit justifies the expansion of these preliminary findings. Figure 2 shows representative miracle fruit seeds with seed coats cracking in response to increasing drying time. In general, seed coats became brittle after $24 \mathrm{~h}$ of drying at $23^{\circ} \mathrm{C}$ thus facilitating their removal. Figure 3 shows germination percentage in response to drying days, incubation temperature, and seed coat presence/absence for miracle fruit seeds. Seed coat, drying days, incubation temperature, and the interaction of drying days and temperature all had

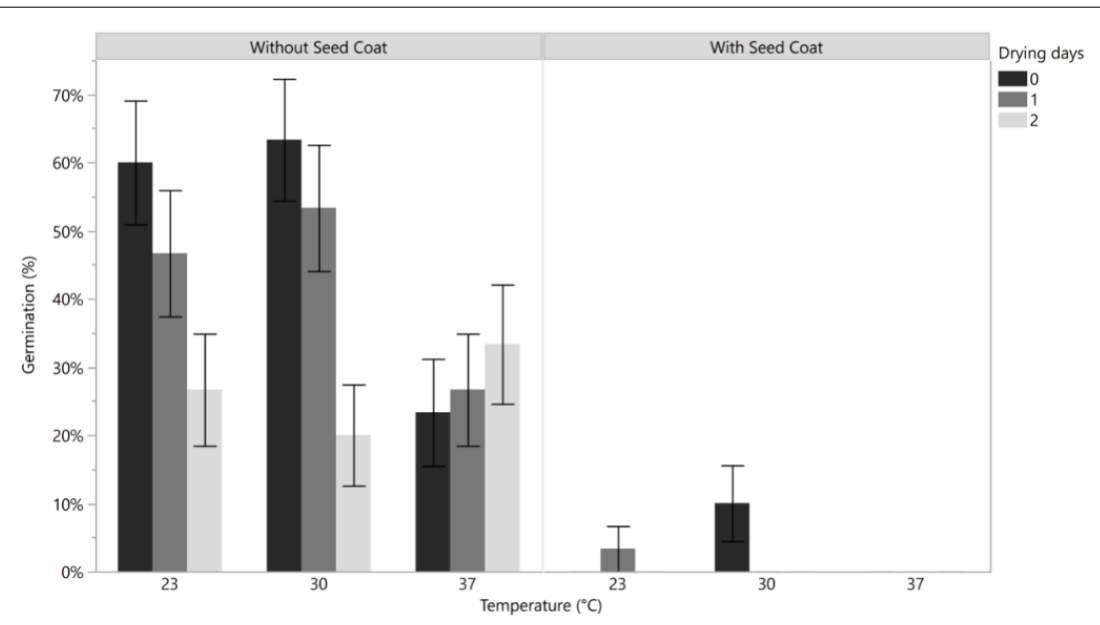

Figure 3: Average germination (\%) of miracle fruit seeds with and without seed coats. Seeds were dried for 0, 1, or 2 days at $23^{\circ} \mathrm{C}$ prior to 10 days incubations at $23^{\circ} \mathrm{C}, 30^{\circ} \mathrm{C}$, or $37^{\circ} \mathrm{C}$. Error bars represent the standard error. All data shown is from three replicates of ten seeds for each treatment. 
significant effects on the seed germination response. The highest rate of seed germination was $63 \%$ at 0 drying days, $30^{\circ} \mathrm{C}$ incubation, and without a seed coat. Germination decreased to $53 \%$ and $20 \%$ by increasing to 1 and 2 drying days, respectively, at $30^{\circ} \mathrm{C}$ without seed coats. Only a few seeds with intact seed coats germinated after incubation for 10 days. The highest percentage of seed germination with seed coats was $10 \%$ when incubated at $30^{\circ} \mathrm{C}$ at 0 drying days.

\section{Seed Coat, Drying Days, and Incubation Temperature Impacts on Root Growth}

Rapid seedling growth is another desirable outcome beyond seed germination. Figure 4 shows the average root length of germinated seedlings for seed coat presence/absence, drying days, and incubation temperatures. Seed coat, drying days, temperature, seed coat*temperature, and seed coat*drying days all have significant effects on root growth.
The optimal condition for maximum root growth (average $8.73 \mathrm{~mm}$ ) was from the treatment with no seed coat, 0 drying days, and incubation at $30^{\circ} \mathrm{C}$. The presence of the seed coat reduced the average root length to $0.43 \mathrm{~mm}$ under the otherwise optimal conditions. Varying the drying days to 1 and 2 days while maintaining the other optimal conditions decreased root length to $6.6 \mathrm{~mm}$ and $2.47 \mathrm{~mm}$, respectively. Varying the optimal conditions for incubation temperatures to $23^{\circ} \mathrm{C}$ and $30^{\circ} \mathrm{C}$ reduced root length to $3.87 \mathrm{~mm}$ and 0.40 $\mathrm{mm}$, respectively.

\section{Seed Coat, Drying Days, and Incubation Temperature Impacts on Shoot Length}

Shoot length is a measure of seedling growth and vigor. Average shoot lengths for germinated seedlings are shown in Figure 5. Overall, shoot growth was less than root growth and fewer seedlings produced shoots than roots after 10 day incubations. All effects and interactions

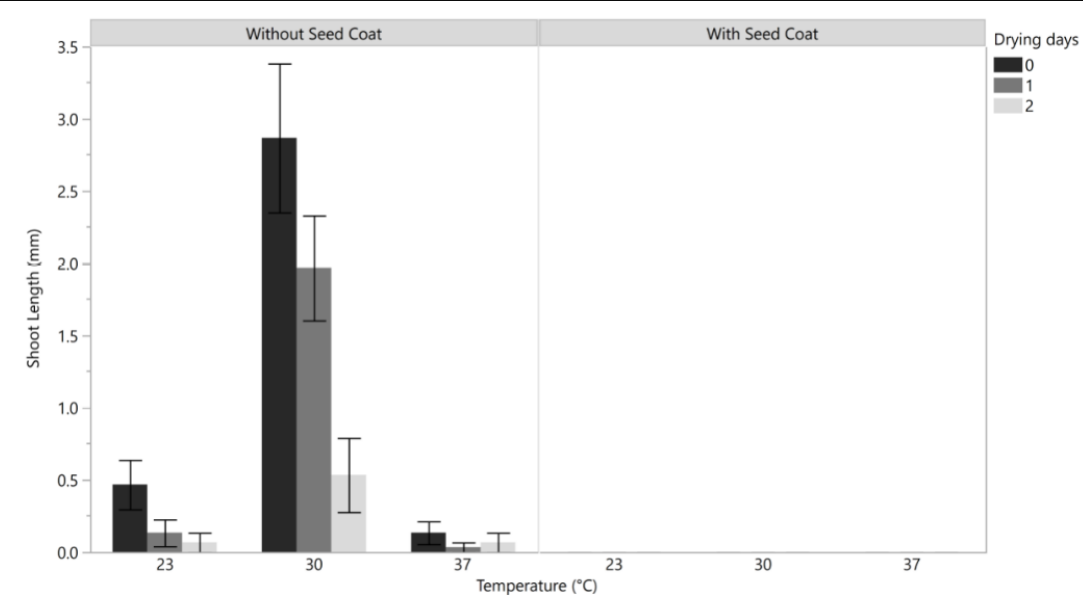

Figure 4: Average root length (in $\mathrm{mm}$ ) of germinated miracle fruit seeds with and without seed coats. Seeds were dried for 0,1 , or 2 days at $23^{\circ} \mathrm{C}$ prior to 10 day incubations at $23^{\circ} \mathrm{C}, 30^{\circ} \mathrm{C}$, or $37^{\circ} \mathrm{C}$. Error bars represent the standard error from three replicates of ten seeds for each treatment.

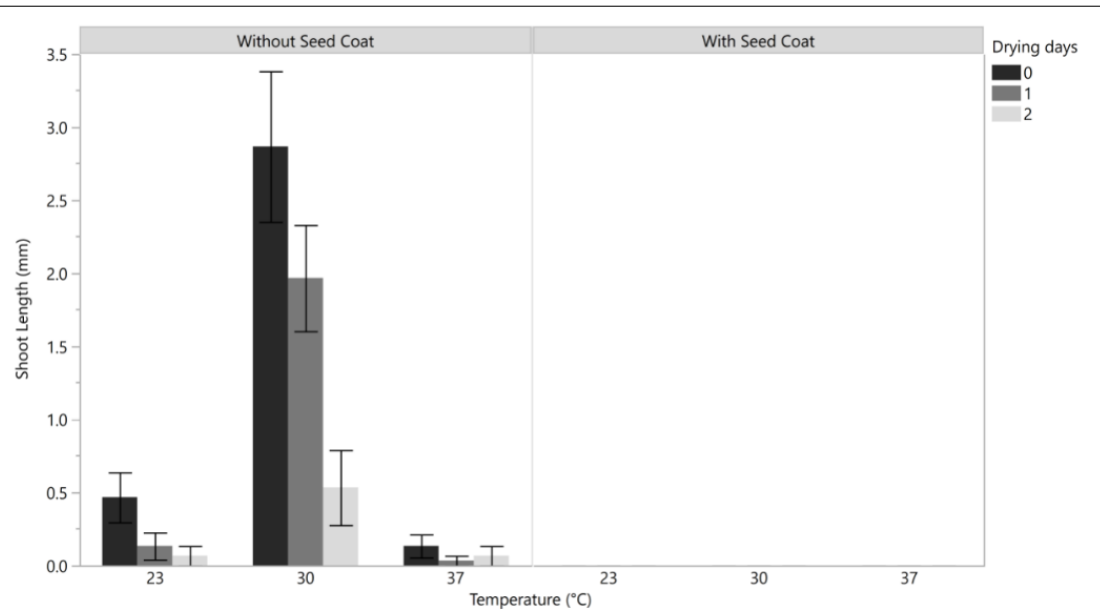

Figure 5: Average shoot length (in $\mathrm{mm}$ ) of germinated miracle fruit seeds with and without seed coats. Seeds were dried for 0,1 , or 2 days at $23^{\circ} \mathrm{C}$ prior to 10 day incubations at $23^{\circ} \mathrm{C}, 30^{\circ} \mathrm{C}$, or $37^{\circ} \mathrm{C}$. Error bars represent the standard error from three replicates of ten seeds for each treatment. 
had significant effects on shoot length including seed coat, drying days, temperature, seed coat ${ }^{\star}$ temperature, and seed coat*drying days, drying days*temperature, and seed coat*drying days*temperature. Similar to root length treatments, the optimal conditions for maximal shoot length were 0 drying days, $30^{\circ} \mathrm{C}$ incubation, and no seed coat. These conditions resulted in an average shoot length of $2.87 \mathrm{~mm}$ compared to no shoot growth for any treatments that had seed coats. Increasing the number of drying days from the optimal conditions resulted in an average shoot length of $1.97 \mathrm{~mm}$ and $0.53 \mathrm{~mm}$ for 1 and 2 drying days, respectively. Changing the incubation temperature from the optimal resulted in average shoot lengths of $0.47 \mathrm{~mm}$ and $0.13 \mathrm{~mm}$ for $23^{\circ} \mathrm{C}$ and $30^{\circ} \mathrm{C}$, respectively.

\section{Irradiation Dose Response}

A species' response to irradiation must be empirically determined, and can vary by genotype within a given species. In general, though, a dose response in one accession of a species can be used to guide irradiation experiments in related accessions. Three hundred miracle fruit seeds were treated with $y$-rays from a Cesium-137 source at 0, 50, 100, 200, 400 and 600 Gy. The results from three replicates of 300 seeds each are shown in Figure 6 . Only seedlings that produced a true leaf after 60 days were counted. The percentage of seedlings producing true leaves from the control sample (no treatment) were $\sim 1 / 3$ that of the optimized germination experiments. The percentage of seedlings producing true leaves decreased as the irradiation dose increased. Total seed mortality was observed at 400 Gy. The LD50 for this experiment was calculated to be $\sim 70 \mathrm{~Gy}$.

\section{Abnormal Seeds}

Two abnormal seed types were observed in each miracle fruit harvest. Representative examples of normal, three cotyledon and double seedlings are shown in Figure 7. Seeds with three cotyledons were observed when removing seed coats for germination experiments. Double seeds were often larger than normal seeds and contained two embryos each with two cotyledons separated by an

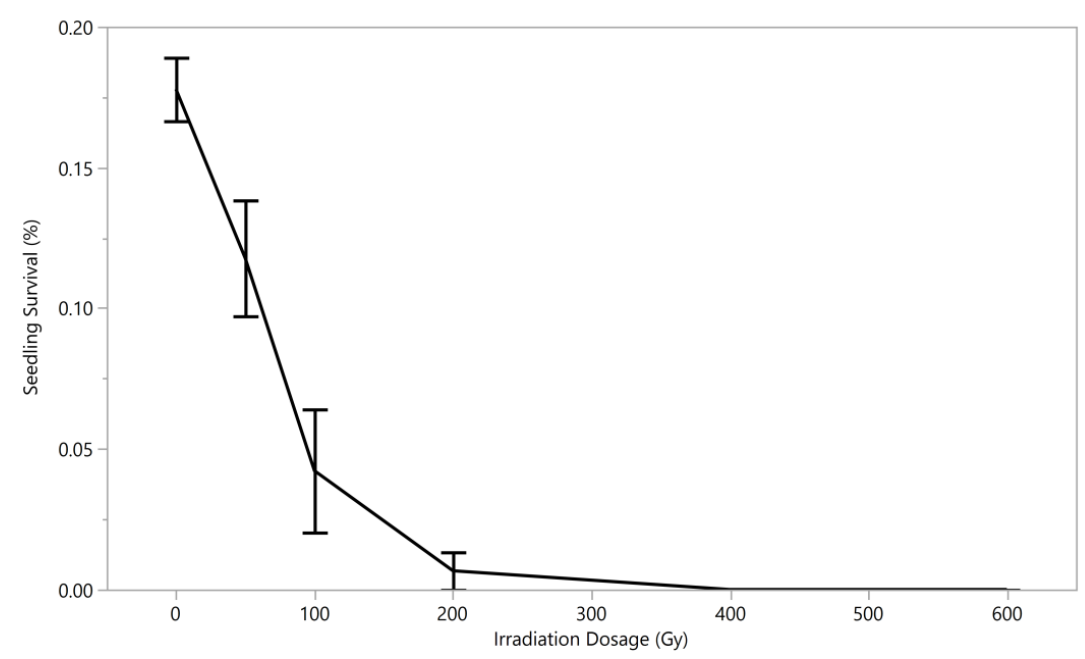

Figure 6: Mutagenesis of miracle fruit seeds using $\gamma$-ray irradiation. Seedling survival was scored 60 days after sowing. Treatment levels included 0, 50, 100, 200, 400 and 600 Gy. Results shown are averages from 300 seeds for each treatment replicated three times. Error bars represent standard error.

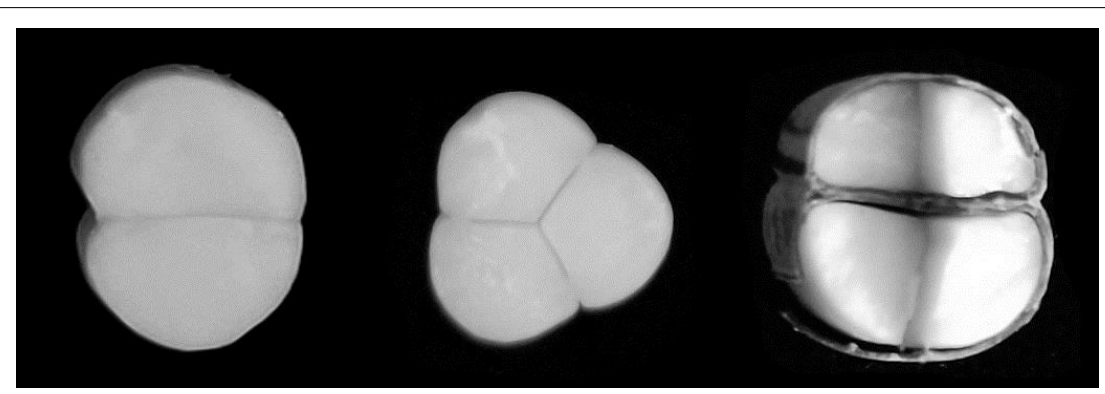

Figure 7: Abnormal miracle fruit seeds found during this study. Representative normal (left), three cotyledon (middle), and double (right) seeds dissected to show cotyledons. Seed coats were removed from both normal and three cotyledon seed for imaging. 
internal seed coat. Three cotyledon and double seedlings germinated as common seed types, and no other abnormalities have been noticed to date. Seeds from a single harvest were used to approximate the frequency of abnormal seeds. 38 out of 1000 seeds (3.8\%) had three cotyledons, and 14 out of 3200 seeds were double seeds (0.43\%).

\section{DISCUSSION}

Preliminary experiments had raised concerns that microbial contamination was negatively impacting seed germination. Surface sterilization treatments showed that only $3 \% \mathrm{H}_{2} \mathrm{O}_{2}$ resulted in an acceptable level of seed germination and low contamination compared to the water control. Other surface sterilization treatments had negative impacts on germination, microbial contamination, or both. The $2 \%$ NADCC treatment reduced germination and increased contamination. The surface sterilization treatments used in this study might actually increase microbial growth by damaging the seed. Overall, contamination could be reduced by removing the seed coat entirely without the application of disinfectant, and this treatment was implemented for the germination and growth treatments in this study.

Removal of the seed coat, decreasing post-harvest drying time, and incubating at $30^{\circ} \mathrm{C}$ increased seed germination to a maximum of $63 \%$, and improved seedling growth rate. Miracle fruit seeds can germinate and produce short roots at $37^{\circ} \mathrm{C}$, but root growth at $37^{\circ} \mathrm{C}$ is inhibited compared to incubation at $23^{\circ} \mathrm{C}$ and $30^{\circ} \mathrm{C}$. Drying seeds for one day at $23^{\circ} \mathrm{C}$ did not have a large impact on seed germination and growth, but it did simplify the removal of seed coats thus reducing a major source of microbial contamination. Efficient germination could be more important when germinating seeds from artificial crosses where each seed represents an investment of time and resources.

A previous study reported miracle fruit seed germination of $79 \%$ at $18^{\circ} \mathrm{C}$ and $79-89 \%$ at $28-30^{\circ} \mathrm{C}$ (Adansi and Holloway, 1975). There were a few key differences in study design and results between this previous study and those presented here. Adansi and Holloway obtained high germination rates after air drying seeds for two days, but their incubation times were longer (15 and 27 days). The major objective of our current study was to optimize conditions for rapid seed germination, and, therefore, ten days was selected as a cut off for germination. The impacts of drying seeds for two days were also very different between these studies. Ambient relative humidity, differences in seed cleaning, and other factors might result in this disparity. Another study investigated the impacts of culture medium (soil or sawdust) on miracle fruit seed germination (Tchokponhoue et al., 2018). This study included incubating miracle fruit seeds (including pulp) at room temperature prior to sowing, and also found that prolonged storage greatly reduced seed germination. These results are in agreement with our work, and demonstrate the rapid decline of miracle fruit seed viability after harvesting. In contrast, our study controlled for post-harvest incubation temperatures, and demonstrated superior germination and seedling growth rate at $30^{\circ} \mathrm{C}$ compared to $23^{\circ} \mathrm{C}$ or $30^{\circ} \mathrm{C}$. This pattern held for larger experiments that included 100 seeds per replicate (data not shown).

Another limitation to miracle fruit plant improvement is the current lack of available genetic diversity. Seed mutagenesis can be used to increase diversity by inducing mutations. Miracle fruit seeds are large and fleshy, and would be predicted to be sensitive to irradiation. This is consistent with the low LD50 at 70 Gy as demonstrated. One major challenge to irradiating miracle fruit seeds is the additional time and lack of environmental control when shipping samples for treatment. The overall germination rate of the radiation control sample was $18 \%$ compared to $63 \%$ for samples under optimal conditions. Still, the germination reduction in response to increasing irradiation dosage demonstrates a treatment effect, and this method could be useful for creating a miracle fruit mutation population for plants. Alternative strategies include chemical-based mutagens like ethyl methanesulfonate that can be used to treat seeds in a lab setting under optimal germination conditions.

\section{CONCLUSIONS}

Miracle fruit is a promising species for forward-looking industries and scientists. The genetic potential of this species is unknown, but increasing commercial interest is driving research efforts to enhance plant productivity. Key to any plant improvement program is an understanding of the species' biological limitations, and readily available genetic diversity to meet current and future crop challenges. This study defined optimized germination and seedling growth conditions for the conditions tested, and established irradiation dosimetry for miracle fruit plant improvement. Additionally, this is the first report of three cotyledon and double seed phenomena in miracle fruit demonstrating how little we know about this species. Regardless, miracle fruit is a unique species with undiscovered potential that could greatly benefit from additional cultural studies and genetic improvement.

\section{ACKNOWLEDGEMENTS}

The authors gratefully acknowledge Miracle Fruit Farm, Homestead, FL for donating miracle fruit seeds for this project. We also acknowledge Christian Collazo for his assistance with seed preparation. 


\section{FUNDING}

This work was supported using startup funds provided by the University Of Florida Dean for Research.

\section{REFERENCES}

Achigan-Dako EG, Tchokponhoué DA, N'Danikou S, Gebauer J, Vodouhè RS (2015). Current knowledge and breeding perspectives for the miracle plant Synsepalum dulcificum (Schum. et. Thonn.) daniell. Genet. Resour. Crop. Evol. 62: 465-476.

Adansi MA, Holloway HL (1975). Germination of seeds of the sweet or miraculous berry Synsepalum dulcificum (Schum. \& Thonn.) daniell. IV Africa Symposium on Horticultural Crops: 181-182.

Ahloowalia BS, Maluszynski M (2001). Induced mutations-A new paradigm in plant breeding. Euphytica. 118(2): 167-173.

Ayensu ES (1972). Morphology and anatomy of Synsepalum dulcificum (Sapotaceae). Bot. J. Linn. Soc. 65(2): 179-187.

Chibuzor IA, Bukola O, Adejoke AO, Chidozie OP (2016). Genetic assessment of the shrub Synsepalum dulcificum (Schumach. \& Thonn.) daniell in Nigeria using the randomly amplified polymorphic dna (RAPD). Int. J. Genet. Genomics. 4(6): 45-50.

Daniell WF (1852). On the Synsepalum dulcificum or miraculous berry of Western Africa. Pharm. J 11: 445-448.

Gibbs BF, Alli I, Mulligan C (1996). Sweet and tastemodifying proteins: A review. Nutr Res 16(9): 16191630.

Inglett GE, Dowling B, Albrecht JJ, Hoglan FA (1965). Taste modifiers, taste-modifying properties of miracle fruit (Synsepalum dulcificum). J. Agric. Food Chem. 13(3): 284-287.
Kant R (2005). Sweet proteins-Potential replacement for artificial low calorie sweeteners. Nutr. J. 4: 5.

Kurihara K, Beidler LM (1968). Taste-modifying protein from miracle fruit. Sci. 161(3847): 1241-1243.

Roychowdhury R, Tah J (2013). Mutagenesis-A potential approach for crop improvement. Crop Improv. 149-187.

Tchokponhoué DA, N'Danikou S, Hale I, Van Deynze A, Achigan-Dako EG (2017). Early fruiting in Synsepalum dulcificum (Schumach. \& Thonn.) daniell juveniles induced by water and inorganic nutrient management. F1000Res 6: 399.

Tchokponhoue DA, Achigan-Dako EG, N'Danikou S, Houdegbe AC, Agossou COA, Assogba-Komlan F, Vodouhe RS (2018). Regeneration ability and seedling growth in the miracle plant Synsepalum dulcificum (Schumach. \& Thonn.) daniell. Fruits. 73(1): 13-21.

Temussi PA (2006). Natural sweet macromolecules: How sweet proteins work. Cell. Mol. Life. Sci. 63(16): 18761888.

Theerasilp S, Hitotsuya H, Nakajo S, Nakaya K, Nakamura Y, Kurjhara Y (1989). Complete amino acid sequence and structure characterization of the tastemodifying protein, miraculin. J. Biol. Chem. 264(12): 6655-6659.

Wilken MK, Satiroff BA (2012). Pilot study of "miracle fruit" to improve food palatability for patients receiving chemotherapy. Clin. J. Oncol. Nurs. 16(5): E173-177.

Wong JM, Kern M (2011). Miracle fruit improves sweetness of a low-calorie dessert without promoting subsequent energy compensation. Appetite 56(1): 163166.

Xingwei C, Abdullah TL, Taheri S, Abdullah NAP, Hassan SA (2016). Flower ontogenesis and fruit development of Synsepalum dulcificum. HortSci. 51(6): 697-702. 